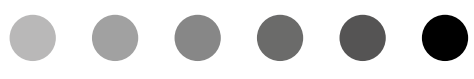

\title{
POLÍTICAS DE INCLUSIÓN/PRÁCTICAS DE SUBALTERNIZACIÓN: LA CONSTRUCCIÓN DE ETNICIDAD EN LOS VILLANCICOS DE NEGROS DE LA CATEDRAL DE SANTIAGO DE GUATEMALA (SIGLOS XVI-XVIII)

\author{
INCLUSION POLITICS/SUBALTERNIZATION \\ PRACTICES: THE CONSTRUCTION OF ETHNICITY \\ IN VILLANCICOS DE NEGROS OF THE CATHEDRAL \\ OF SANTIAGO DE GUATEMALA (16TH-18TH \\ CENTURY)
}

Deborah Singer*

\begin{abstract}
Resumen: Este artículo problematiza la noción de etnicidad subyacente en los villancicos de negros del Archivo Histórico Arquidiocesano de Guatemala (AHAG). A pesar de que se trata de piezas musicales que proyectan la idea de armonía social en un contexto festivo, lo cierto es que emergen identidades en conflicto con el poder colonial, sobre la base de un discurso ambivalente que consolida y naturaliza estereotipos raciales.
\end{abstract}

Palabras claves: música colonial; etnicidad; subalternidad; afrodescendientes; identidad cultural; discurso; historia; Guatemala.

Abstract: This paper problematizes the notion of ethnicity underlying in villancicos de negros that are sheltered in Guatemala's Archidiocesan Historical Archive. Despite being musical pieces that project the idea of social harmony, they enable the emergence of identities in conflict with the colonial power, based on an ambivalent discourse that consolidates and naturalizes racial stereotypes.

Keywords: Colonial Music; Ethnicity; Subalternity; Afro descendants; Ethnic Identity; Speeches; History; Guatemala. 
“[...] eso que se llama el alma negra es una construcción del blanco". Frantz Fanon ${ }^{1}$

\section{Introducción}

$\mathrm{E}$

n los siglos XVII y XVIII la Catedral de Santiago de Guatemala ocupó un lugar relevante en la producción de piezas de música. ${ }^{2}$ A partir de la huella que dejó el músico español Hernando Franco -1570-, numerosos maestros de capilla se dieron a la tarea de crear obras polifónicas para otorgar realce a las fiestas, atraer a los fieles a los servicios religiosos y -a la vez- reafirmar la hegemonía de la Iglesia y la Corona. ${ }^{3}$ Dentro de la variada producción musical de la época se destacan los villancicos de negros, conocidos también como guineos, o negrillas. Las características de este subgénero del villancico han sido detalladas en trabajos previos, ${ }^{4}$ cuyos autores destacan sobre todo la construcción del negro como sujeto cándido, inocente y desbordante de alegría. En el caso de las negrillas de navidad, la temática gira en torno de un grupo de negros que parte rumbo al portal de Belén para alegrar al Niño con sus regalos, músicas y danzas, en medio de un emotivo despliegue de devoción cristiana.

Las negrillas suelen tener un formato responsorial para recrear el diálogo entre el solista y el coro de negros; además, abundan las síncopas, onomatopeyas y diferentes combinaciones rítmicas que, por una parte, buscan generar un

1 Frantz Fanon, Piel negra, máscaras blancas (Madrid, España: Ediciones Akal, 2009), 46.

2 Este artículo fue elaborado gracias al apoyo de la Dirección de Investigación de la Universidad Nacional, Costa Rica, que me permitió realizar una visita al Archivo Histórico Arquidiocesano "Francisco de Paula García Peláez" de Guatemala. Mi más sincero reconocimiento al personal que trabaja en el Archivo y al musicólogo guatemalteco Omar Morales Abril. Algunos aspectos de este tema los presenté en el $I V$ Congreso Centroamericano de Estudios Culturales, realizado en San José de Costa Rica, del 17 al 19 de julio del año 2013.

3 Para mayor información respecto de los maestros de capilla de Santiago de Guatemala, véase Omar Morales Abril, "Villancicos de remedo en la Nueva España", en: Humor, pericia y devoción en la Nueva España, (ed.) Aurelio Tello (Oaxaca, México: CIESAS, 2013), 11-38; Robert Snow. A New World Collection of Polyphony for Holy Week and the Salve Service (Ciudad de Guatemala, Cathedral Archive, Music MS 4: The University of Chicago Press, 1996), 1-78; Dieter Lehnhoff, "Letra y música en los villancicos de maitines de Rafael Antonio Castellanos", Cultura de Guatemala (Guatemala) Segunda Época, año XXIV, vol. 3 (septiembre-diciembre, 2003): 41-66; Dieter Lehnhoff, Creación musical en Guatemala (Ciudad de Guatemala, Guatemala: Editorial Galería Guatemala, 2005), 69-85; Alfred Lemmon, "Las obras musicales de dos compositores guatemaltecos del siglo XVIII: Rafael Antonio Castellanos y Manuel José de Quiróz”, Mesoamérica (Guatemala). 5, n. 8, (1984): 389-401, disponible en: https://dialnet.unirioja.es/servlet/ articulo? codigo $=4009137$

4 Véase: Robert Stevenson, “The Afro-American Musical Legacy to 1800”, The Musical Quarterly (EE. UU.) 54, n. 4 (octubre, 1968), 475-502, en: https://www.jstor.org/stable/i229642; Samuel Claro, Antología de la música colonial en América del Sur (Santiago, Chile: Ediciones de la Universidad de Chile, 1974); Ángel M. Aguirre, "Elementos afronegroides en dos poemas de Luis de Góngora y Argote y en cinco villancicos de Sor Juana Inés de la Cruz", Atti del Convegno di Roma (Associazione ispanisti italiani), vol. 1 (1996), 295-311, en: https://cvc.cervantes.es/Literatura/aispi/pdf/07/07_293.pdf; Natalie Vodovozova, A Contribution to the History of the Villancico de Negros (Tesis de Maestría en Artes, The University of British Columbia, 1996); Glenn Swiadon, "Fiesta y parodia en los villancicos de negro del siglo XVII", Anuario de Letras: Lingüistica y Filología (México) 42 (2011): 285-304, disponible en: https://dialnet. unirioja.es/servlet/articulo? codigo $=2272692$ 
resultado sonoro vivaz y, por otro lado, proyectan la idea de que los negros tienen una "inclinación natural" hacia la música y las danzas. El lenguaje que utilizan los negros de estos villancicos es un español deformado en el que se sustituyen u omiten letras y abundan los errores de conjugación, concordancia, tiempo verbal, etc. Dado que se trata de rasgos distintivos que eran atribuidos a todos los afrodescendientes, intentaré explorar qué categorías entran en juego al configurar una noción de etnicidad en la que el color de la piel es el punto de partida para definir estereotipos de la diferencia.

\section{Fuentes}

Como fundamento de análisis examinaré diecisiete negrillas que se encuentran en el AHAG. Se trata de obras a cuatro o cinco voces, algunas de ellas con las partes del acompañamiento instrumental: violines 1 y 2, bajo bajón-, trompas, clarines y continuo. Las piezas son las siguientes:

- $\quad$ Cavayeroz, tulo neglo ezté puntual ${ }^{5}$-sin fecha, n. ${ }^{\circ} 188$ del catálogo, 5 voces-, pieza anónima.

- Antoniya, Flaciquiya, Gacipá -sin fecha, n. ${ }^{\circ} 383$ del catálogo, 5 voces-, del portugués Fray Felipe de la Madre de Dios (1626-1675).

- $\quad$ Pascualillo que me quieles -sin fecha, signatura 233, villancico a dúo-, del maestro de capilla de la catedral de Puebla, Mateo Dallo y Lana (1650-1705).

- Negliya que quele -1698, n. $^{\circ} 260$ del catálogo, 4 voces- y Siolo helmano Flacico-sin fecha, ${ }^{6} \mathrm{n} .{ }^{\circ} 264$ del catálogo, 4 voces-, del compositor y maestro de capilla español Sebastián Durón (1660-1716). ${ }^{7}$

- $\quad$ Digo a siola negla -1736, n. $^{\circ} 636$ del catálogo, coplas solas y a 4 voces-, Jesuclisa Mangalena -1745, n. ${ }^{\circ} 619$ del catálogo, 5 voces- y Venga turo Flanciquillo -1746, n. ${ }^{\circ} 618$ del catálogo, 5 voces-, villancicos del compositor y maestro de capilla nacido en Santiago de Guatemala, Manuel Joseph de Quirós (¿? - 1765).

5 El texto de este villancico también se encuentra en Joseph Pérez de Montoro, Obras Posthumas Lyricas Sagradas (Madrid, España: Oficina de Antonio Marin, 1736), 392-394. Forma parte de los que se cantaron en la catedral de Cádiz en la navidad de 1694.

6 Aunque en el manuscrito consta que se cantó en 1738.

7 Sebastián Durón fue organista y maestro de capilla de las Catedrales de Sevilla, Cuenca, el Burgo de Osma y Palencia. En 1691 lo nombraron maestro de la Real Capilla del Rey en Madrid. El puesto lo perdió en 1706 por su apoyo explícito al archiduque Carlos de Austria en contra del candidato borbónico y futuro rey Felipe V. 
- Turu turu lo nenglito -sin fecha, n. ${ }^{\circ}$ S900 del catálogo-, pieza anónima. ${ }^{8}$

- $\quad$ Ah, siolos molenos -sin fecha, n. ${ }^{\circ} 419$ del catálogo, 4 voces-, de Gabriel García de Mendoza (ca. 1705-1738).

- Pue tambén somo gente -sin fecha, n. ${ }^{\circ} 796$ del catálogo, 4 voces-, del compositor oaxaqueño Tomás Salgado (1698-1751).

- $\quad$ Diga plimiya -1761, n. ${ }^{0}$ 57A del catálogo, 4 voces-, A siñola plima mia ${ }^{9}$ (1773, n. ${ }^{\circ} 100$ del catálogo, 5 voces), Lo neglo que somo gente ${ }^{10}-1787$, n. ${ }^{\circ} 169$ del catálogo, 5 voces-, Afuela afuela ${ }^{11}-1788$, n. $^{\circ} 174$ del catálogo, 4 voces-, El negro Maytinero -sin fecha, n. ${ }^{\circ} 90$ del catálogo, 5 voces- y Negros de Guaranganá -1788, n. ${ }^{\circ} 179$ del catálogo, 4 voces-, todos villancicos del compositor y maestro de capilla nacido en Santiago de Guatemala, Rafael Antonio Castellanos (1725- 1791).

A excepción de Negliya que quele -Sebastián Durón-, impresa en Madrid en 1722 , todas las piezas son copias en manuscrito. He optado por conservar la ortografía original, aunque en numerosas ocasiones los compositores no son consistentes al intentar reproducir el español hablado por los negros, de modo que un mismo vocablo puede aparecer escrito de diferentes formas en un mismo villancico.

\section{Generalidades de los villancicos}

El villancico es un género literario y musical que floreció en España a partir del siglo XV. Se trata de cantos que los aldeanos -villanos- cantaban en lengua vernácula, se alternaba el estribillo con un número variado de coplas. En sus orígenes los temas de los villancicos eran seculares y hacían referencia a la vida diaria de las personas, pero poco a poco fueron incorporando motivos religiosos $\mathrm{y}$, debido a su gran popularidad, lograron introducirse en los oficios de maitines de la Iglesia, en reemplazo de los responsorios en latín. ${ }^{12}$

8 En la portada se lee Juguete de navidad.

9 En la portada del manuscrito está escrito: "Fue a Nunualco a Manuel Dávila". Según información que me proporcionó el musicólogo Omar Morales Abril, en el AHAG hay al menos cinco obras que Castellanos envió a Manuel Dávila, residente de Santiago Nonualco, El Salvador. Cabe señalar que en el AHAG hay otra versión de este villancico que tiene por título Ah, señola plima mia, atribuída al maestro de capilla Nicolás Márquez Tamariz -expediente n. ${ }^{\circ} \mathrm{S} 938$ -

10 El texto de este villancico es similar al que aparece en la publicación de Pérez de Montoro, Obras Posthumas..., 284-287. Fue cantado en la Catedral de Cádiz en la Navidad de 1689.

11 Sería interesante seguirle la huella al texto de este villancico en otras catedrales hispanoamericanas.

12 El cambio es atribuido a Fray Hernando de Talavera, arzobispo de Granada y ex confesor de la reina Isabel la Católica. Véase Aurelio Tello, "Sor Juana Inés de la Cruz y los maestros de capilla catedralicios o de los ecos concertados y las acordes músicas con que sus villancicos fueron puestos en métrica armonía”, Pauta (México) 16, n. 57-58 (enero-junio, 1996), 15. 
Políticas de inclusión/prácticas de subalternización: la construcción de etnicidad en los villancicos de negros de la Catedral de Santiago de Guatemala (siglos XVI-XVIII)

El género era adaptable a las necesidades específicas de cada ocasión litúrgica por su gran flexibilidad estructural, lo que permitía realizar contrafactas, al combinar poesía, música y danza con los elementos teatrales de la mojiganga ${ }^{13}$. Esto es particularmente visible en los villancicos de remedo, que buscan imitar de manera jocosa a distintos grupos sociales, como los letrados, sacristanes, franceses, portugueses, indígenas, negros, etc. Este tipo de villancico integra a todos los actores de la sociedad en el marco efímero y lúdico de las fiestas. No obstante, como género literario siempre permaneció en una posición subalterna que -según indica Mabel Moraña ${ }^{14}$-a la larga resultaba similar a la posición que ocupaban los sujetos cuya voz el villancico proyectaba. Puesto que este trabajo se centra específicamente en la configuración que en los villancicos de negros se da a los afrodescendientes, el enfoque lo haré desde la perspectiva de la etnicidad, concretamente, en las categorías que intervienen para definir la diferencia del otro.

\section{Estereotipos de la diferencia}

Proporcionar una definición de etnicidad es en extremo complejo porque el concepto suele ser utilizado de manera confusa y admite múltiples aproximaciones..$^{15} \mathrm{~A}$ partir del ángulo de análisis, cada investigador se centra en aspectos

13 La inclusión no estuvo exenta de polémica. Hasta fines del siglo XV los villancicos fueron combatidos por muchos religiosos porque según señalaban, más movían a la diversión que al recogimiento. Así lo expresa un canónigo de aquella época en la catedral de Granada: "No es posible tolerar que... se canten las alabanzas a Dios de un modo tan irreverente e indecoroso... En la noche de navidad introducen en los villancicos tantos pensamientos extravagantes e indecentes, y tratan los asuntos más altos en el estilo más bajo y soez, lleno de bufonadas propias de la infame plebe... las malas coplas profanas introducen y mantienen el mal gusto y la irreverencia”. Véase: German Tejerizo Robles, Villancicos Barrocos en la Capilla Real de Granada (Sevilla, España: Editoriales Andaluzas Unidas S. A., 1989), 82.

14 Mabel Moraña, "Poder, raza y lengua: la construcción étnica del Otro en los villancicos de sor Juana", en: Viaje al silencio. Exploraciones del discurso barroco (México, D.F.: UNAM, 1998), en: http:// www.cervantesvirtual.com/obra-visor/viaje-al-silencio-exploraciones-del-discurso-barroco--0/html/e $5 \mathrm{~b}$ 96feb-bf21-4bd2-be1c-9389af0cb0ba_55.html

15 Véase: Carter Bentley, "Ethnicity and Practice", Comparative Studies in Society and History, 29, n. 1 (enero, 1987), 24-55, DOI: https://doi.org/10.1017/S001041750001433X; Joane Nagel, "Constructing Ethnicity: Creating and Recreating Ethnic Identity and Culture”, Social Problems (Reino Unido) 41, n. 1 (febrero, 1994), 152-176, DOI: https://doi.org/10.2307/3096847; Eduardo Bonilla Silva, "Rethinking Racism: Toward a Structural Interpretation", American Sociological Review (EE. UU.) 62, n. 3 (enero, 1997), 465-480, DOI: https://doi.org/10.2307/2657316; Hal B. Levine, "Reconstructing Ethnicity", Journal of the Anthropological Institute (Reino Unido) 5, n. 2 (enero, 1999), 165-180, DOI: https:/doi. org/10.2307/2660691; Simon Dein, "Race, Culture and Ethnicity in Minority Research: A Critical Discussion", Journal of Cultural Diversity (EE. UU.) 13, n. 2 (2006), 68-75; Andreas Wimmer, "The Making and Unmaking of Ethnic Boundaries: A Multilevel Process Theory", American Journal of Sociology (EE. UU.) 113, n. 4 (enero, 2008), 970-1022, DOI: https://doi.org/10.1086/522803; Rogers Brubaker, "Ethnicity, Race and Nationalism", Annual Review of Sociology (EE. UU.) 35 (2009), 21-42, DOI: https:// doi.org/10.1146/annurev-soc-070308-115916; Tomás R. Jiménez, “Affiliative Ethnic Identity: A More Elastic Link Between Ethnic Ancestry and Culture”, Ethnic and Racial Studies, 33, n. 10 (abril, 2010), 1756-1775, DOI: https://doi.org/10.1080/01419871003678551; Emily M. Stovel, "Concepts of Ethnicity and Culture in Andean Archaelology", Latin American Antiquity (Reino Unido) 24, n. 1 (marzo, 2013), 3-20, DOI: https://doi.org/10.7183/1045-6635.24.1.3; Federico Navarrete Linares, Hacia otra historia de 
específicos, como la apariencia física, el ancestro, la historia común y las narrativas que dan sentido a los eventos del pasado, el lugar de origen, la cultura -es decir, los símbolos y prácticas en torno de los cuales el grupo se cohesiona-, afiliaciones, estereotipos, exclusión social, en fin; la lista es larga. Un factor que ha sido frecuentemente señalado es el situacional: las personas asumen determinadas etnicidades desde las situaciones a las que se ven confrontadas en la vida diaria. ${ }^{16}$ Dicho en otras palabras, la etnicidad es más un asunto relativo a los procesos mediante los cuales las fronteras étnicas son creadas, que al contenido de sus categorías. ${ }^{17}$ No obstante, las diferencias fenotípicas suelen ser el principal marcador de la alteridad, lo que ha derivado en el reconocimiento de "razas" como un subtipo de la etnicidad, independientemente de lo difusa que se torna la línea que las define y delimita. ${ }^{18}$ Es por eso que algunos marcos de análisis proponen el concepto de sistemas sociales racializados, refiriéndose a los niveles políticos, económicos, sociales e ideológicos que se estructuran parcialmente a partir de la localización de los actores en categorías raciales. Esto involucra formas de jerarquías que determinan el modo en que se posicionan y relacionan las razas. ${ }^{19}$

Los modos de clasificar han estado siempre ligados a prácticas de colonización, esclavitud y servilismo, puesto que establecen patrones de acción que se activan en circunstancias determinadas, conforme se trate de "nosotros" -el poder-o de "ellos" -los grupos subalternos-. La cultura del otro opera como un componente adicional fundamental en la diferenciación, puesto que permea e institucionaliza las relaciones sociales, al consolidar ciertas hegemonías y al establecer fronteras de exclusión. Así se explica que la diferencia cultural suela ser magnificada: "Después de que una sociedad se vuelve racializada, un set de relaciones sociales y prácticas basadas en distinciones raciales se desarrolla en todos los niveles sociales". ${ }^{20}$

Galen Bodenhausen y Jennifer Richeson ${ }^{21}$ sostienen que la diferenciación racial trae consigo representaciones colectivas del otro que se traducen en estereotipos; estos circulan a través de los discursos, lo que da origen a memorias narrativas que crean efectos de lo real con resultados de estereotipación:

América. Nuevas miradas sobre el cambio cultural y las relaciones interétnicas (México, D.F.: Instituto de Investigaciones Históricas, UNAM, 2015), disponible en: http:/www.historicas.unam.mx/publicaciones/ publicadigital/libros/otrahistoria/hoha003_cambio.pdf

16 Nagel, “Constructing Ethnicity...", 154.

17 Dein, "Race, Culture and Ethnicity...", 72.

18 Wimmer, "The Making and Unmaking...,", 974.

19 Esta aproximación teórica es desarrollada por Bonilla Silva en "Rethinking Racism...", 469.

20 "After a society becomes racialized, a set of social relations and practices based on racial distinctions develops at all societal levels". La traducción es mía. Ibid., 474.

21 Galen Bodenhausen y Jennifer A. Richeson, "Prejudice, Stereotyping, and Discrimination", en: Advanced Social Psychology, (eds.) R. F. Baumeister y E. J. Finkel (Oxford, Reino Unido: Oxford University Press, 2010), 341- 383. 
"A stereotype can be defined as a generalized belief about the characteristics of a group, and stereotyping represents the process of attributing these characteristics to particular individuals only because of their membership in the group. Whereas prejudice involves a global evaluative response to a group and its members, stereotyping consists of a much more specific, descriptive analysis". ${ }^{22}$

La complejidad de la etnicidad y la estereotipación se debe a que en cualquier definición priman supuestos ambiguos y contradictorios que inciden en la respuesta frente a las minorías, de manera que con frecuencia no se reconoce en el otro comportamientos que son inconsistentes con las expectativas previas. ${ }^{23} \mathrm{La}$ otredad se yergue como una realidad social visible y predecible que siempre da pie a una nueva versión de algo conocido de antemano. Esa repetibilidad -re-presentación- en coyunturas históricas cambiantes crea efectos de verdad que derivan en estrategias de individuación y marginalización. ${ }^{24}$ Rogers Brubaker ${ }^{25}$ da un paso adelante al poner en tela de juicio la noción misma de "grupos étnicos" como realidad inobjetable, vale decir, aquellas colectividades delimitadas cuyos miembros se reconocen entre sí, comparten una identidad corporativa y tienen capacidad para la acción concertada. ${ }^{26}$ Pensar en términos de grupo implica que al invocarlos se los "invita al ser" y con eso se contribuye a producir lo que aparentemente se está describiendo; se trata entonces de otra forma de esencializar -y estereotipar- al otro. Este fenómeno se observa en el reconocimiento de las razas; en realidad las razas no "están" en el mundo, sino que son perspectivas sobre el mundo, de manera que la tarea de cualquier analista debería consistir en descubrir qué lleva a codificar en clave de etnicidad, qué intereses están en juego, cuáles son los principios de diferenciación del espacio social que está siendo observado y qué estructuras de poder son las que priman. ${ }^{27} \mathrm{El}$ hecho concreto es que las poblaciones afrodescendientes han sido y aún siguen siendo clasificadas conforme a categorías sociales con un fuerte componente racial: negro, moreno, mulato, morisco, pardo y zambo, entre otras.

22 "Un estereotipo puede ser definido como una creencia generalizada acerca de las características de un grupo, y estereotipar representa el proceso de atribuir estas características a individuos particulares sólo por su pertenencia al grupo. Mientras el prejuicio involucra una respuesta evaluativa global a un grupo y sus miembros, estereotipar consiste en un análisis mucho más específico, descriptive". La traducción es mía. Ibid., 345.

23 Diane M. Mackie y David L. Hamilton, Affect, Cognition and Stereotyping. Interactive Processes in Group Perception (San Diego, EE. UU.: Academic Press, INC, 1993), 379.

24 Homi Bhabha, El lugar de la cultura (Buenos Aires, Argentina: Ediciones Manantial, 2002), 91.

25 Rogers Brubaker, "Etnicidad sin grupos”, en: Las máscaras del poder. Textos para pensar el Estado, la etnicidad y el nacionalismo, (ed.) Pablo Sandoval (Lima, Perú: Instituto de Estudios Peruanos, 2017), 425-463.

26 Ibid., 433.

27 Pierre Bourdieu, Razones prácticas. Sobre la teoría de la acción (Barcelona, España: Editorial Anagrama, 1997), 48 . 


\section{De Guinea, de Angola y de Congo}

A simple vista pareciera ser que el lugar de origen es un criterio natural para definir la etnicidad. Adscribir al otro a coordenadas geográficas específicas - ¿lejanas?- establece que "ellos no pertenecen aquí", noción que circula a través de discursos y se reafirma institucionalmente, al margen de los niveles de inserción social que la minoría en cuestión tenga en el lugar de residencia.

Es sabido que la mayor parte de los negros embarcados como esclavos con destino a América procedían de la región centro-occidental de África. ${ }^{28}$ Independientemente de las diferencias lingüístico-culturales de los esclavos -bantú, mandinga, yoruba, etc.--, ciertos topónimos -Guinea, Angola, Congo- operaron en Occidente como genéricos para representar el "lugar" de los negros. Esta característica puede observarse en los villancicos analizados en este trabajo. Por ejemplo, la tropa militar que emerge en Afuela afuela está al servicio del Rey de Guinea. ${ }^{29}$ De Angola procede el grupo de negros de los villancicos Digo a siola negla, Siolo helmano Flacico, Diga plimiya y Pue tamben somo gente, mientras que los negros de Turu turu lo neglito provienen del Congo. Hay algunos de estos cantos en los que se menciona lugares ignotos: Guaranganá -en el villancico Negros de Guaranganá- y Zambanbú o Carambú -villancico Diga plimiya-, que en el contexto de los villancicos funcionan como sinécdoque de África en su totalidad. ${ }^{30}$ Agrupar comunidades múltiples en una única entidad étnica, grande y homogénea -África- tiene como resultado la negación de los rasgos identitarios locales y el reconocimiento de un supuesto nexo entre el lugar de origen y la diferencia racial. Lo cierto es que en la sociedad colonial imperaban modos de clasificación que los obligaban a identificarse dentro de la categoría de negros, por más que trataran de contrarrestar el estigma de la negritud. Esa homogeneidad impuesta no les dejaba otras opciones de identificación y sus efectos eran subalternizadores. ${ }^{31}$

Otro elemento marcador de etnicidad es el nombre que los amos de Occidente impusieron a sus esclavos africanos. Además de la violencia simbólica que significó arrebatarles el nombre de raigambre africana, este proceso de cristianización fue naturalizado en los villancicos mediante una avalancha de nombres "típicos" de los negros, que además de aparecer una y otra vez, son deformados

28 Véase: Robin Law, "La costa de los esclavos en África Occidental", en: Rutas de la esclavitud en África y América Latina, (comp.) Rina Cáceres (San José, Costa Rica: EUCR, 2001), 29-43; Elisée Soumonni, "Ouidah dentro de la red del comercio transatlántico de esclavos", en: Rutas de la esclavitud en África y América Latina, (comp.) Rina Cáceres (San José, Costa Rica: EUCR, 2001), 21-28.

29 Aprovecho de destacar que al Niño no le cantan una tonadilla de Guinea, sino de Angola -"con toniya de Angola le ploculamo reposo"-.

30 Marcella Trambaiolli, "Apuntes sobre el guineo o baile de negros: tipología y funciones dramáticas", Memoria de la palabra. Actas del VI Congreso de la Asociación Internacional Siglo de Oro (2002), 17731783, en: https://cvc.cervantes.es/Literatura/aiso/pdf/06/aiso_6_2_072.pdf

31 Véase Dein, "Race, Culture and Ethnicity...", 72. 
mediante la sustitución u omisión de letras. Se trata de una estrategia adicional para reforzar la idea de adscripción de los negros al grupo en cuestión. Tal es el caso de las variantes de Francisco -Flacico, Flancico, Flaciquilla, Flaciquillo o Flanciquillo-, Antonio -Antón, Antoniyo, Antona y Antonilla-, así como Gaspar -Gaspala, Gazipal, Gazipala, Gaspariya, Gaspá-. Otros nombres que se repiten son Manuel, Pascual -Pascuá, Pascualillo-y Tomé - Tumé-. En el caso de Jileta, Cazilda, Pantuflo, Maltin y Jesuclisa Mangalena, aparecen una única vez en los villancicos revisados en este trabajo. Cabe señalar que los diminutivos -como Jorgiyo, Pascualillo, Antoniyo, plimiyo o negliyo- marcan una condescendencia paternalista que -a mi modo de ver-constituye otra forma de subalternizar, en la medida en que se dispensa al negro el trato que reciben los menores de edad.

\section{El habla de los negros}

Del mismo modo en que los nombres se transforman en estereotipaciones, la omisión o sustitución de letras en el habla cotidiana de los negros es otro rasgo de etnicidad: ellos se expresan en un español deformado que ya los autores del Siglo de Oro reconocían como habla de los negros. Quevedo señala con cierta dosis de humor que para mostrar conocimiento de la lengua de Guinea solo hay que cambiar la "r" por la "l", y viceversa. ${ }^{32}$ A esto habría que agregar los errores de concordancia de género y número, de conjugación verbal, la omisión de artículos, de preposiciones, de la última consonante de la palabra, etc. ${ }^{33}$

John Lipski ${ }^{34}$ señala que en el siglo XVI muchas de estas características eran comunes en el habla de Andalucía, Extremadura e Islas Canarias, ${ }^{35}$ lo que abre interrogantes respecto de las variantes sociolingüísticas y etnolingüísticas que fueron producto de la interacción socio-cultural y que podrían demostrar que la dicha homogeneidad del habla de los negros es más bien una construcción literaria. ${ }^{36}$ De hecho, estos villancicos se ciñen a todas las características ya señaladas. Por ejemplo, véase el Tiple I de la primera copla de $A$ siñola plima mia:

\footnotetext{
"Vamo al Poltalillo plesta

Llegalemo como etamo

Que si neglo ayá no vamo

No vale nara la festa".
}

32 Francisco de Quevedo, Obras de Francisco Quevedo Villegas (Madrid, España: Joachim Ibarra Impresor, 1772), 230.

33 Véase: Aguirre, "Elementos afronegroides...", 297-298 y Vodovozova, A Contribution to the History..., 109-114.

34 John Lipski, "Literary 'Africanized' Spanish as a Research Tool: Dating Consonant Reduction”, Romance Philology (EE. UU.) 49, n. 2 (noviembre, 1995), 130- 167, disponible en: http://php.scripts.psu.edu/faculty/j/m/jml34/afrodate.pdf

35 Ibid., 144.

36 Véase: Jorge E. Porras, "Mexican Bozal Spanish in Sor Juana Inés de la Cruz's Villancicos: A Linguistic and Sociolinguistic Account", The Journal of Pan African Studies (EE. UU.) 6, n. 1 (julio, 2013), 157-170. 
Se observa la omisión sistemática de la "s" -vamo, etamo-, se sustituye la "r" por la "l" -neglo, plesta- y se distorsionan palabras -festa en vez de fiesta-. Nótese además la asociación que existe entre los negros y la alegría. En Venga turo Flaciquillo hay sustituciones de la "d" por la "l": "Vamo aya, vamo aya/ oíl, oíl, oíl, milá, milá" -en vez de "oid, mirad"- y en Pue tambén somo gente los negros no saben contar correctamente en español: "Una, dosa, cuatlo cinco". Puesto que los villancicos de negros no fueron creados por los mismos negros quienes tampoco eran el público meta-, negarles la posibilidad de hablar correctamente la lengua hegemónica es ponerlos en condición de carencia e inferioridad. Esto da origen a una etnicidad lingüística que es mediada por un letrado. Incluso en la introducción del villancico Negros de Guaranganá se habla de un grupo de negros que comienza "con su media lengua a refunfuñar".

En las negrillas cada individuo es transformado en ejemplar de un colectivo con patrones uniformes de comunicación y eso impide a los negros introducir variantes lingüísticas válidas, conforme a sus propios códigos culturales. Visto así, los villancicos promueven un discurso que orienta la percepción externa acerca de la minoría étnica, sin considerar las voces internas de esta. Con ello no solo se magnifica la diferencia, ${ }^{37}$ sino que también se distorsiona la comunicación con el otro.

\section{Entre risas y expresiones devocionales}

¿En qué momento las risas y alegrías fueron transformadas en elementos constitutivos de la etnicidad afrodescendiente? El mensaje que trasciende es que la misión "natural" de los negros es divertir a la concurrencia. Lo cierto es que en los villancicos suele haber una alegría permanente que se manifiesta en carcajadas, juegos onomatopéyicos o jitanjáforas que generan un resultado sonoro alegre y vivaz. Por ejemplo, en Negliya que quele los negros cantan: "Zezú, zezú, que aleglia zezú, nos da nuezoz Reyes, zezú, zezú”. Asimismo, en Siolo helmano Flacico se destacan las interjecciones "Acha á, acha é, ay Jesú Malia y Jusé, Malia y Jusé, uluá, ulué, alalilayle".

En algunos casos la risa es provocada por situaciones bochornosas que experimentan los negros -en Afuela afuela y Turu turu lo Neglito uno de ellos es mordido por una mula- o porque alguno se atreve a situarse en condición de superioridad respecto de sus compañeros. En El negro Maytinero, el tata Pascual -un anciano que es descrito como fiscal de algún lugar- se da ínfulas de ser docto en gramática -“Griamatrica"-, leyes, música y latín. ${ }^{38}$ Por eso pretende

37 Levine, "Reconstructing Ethnicity", 169.

38 Este personaje tipo también está presente en los villancicos de negros de Sor Juana Inés de la Cruz. Véase: Alfonso Méndez Plancarte, Obras completas de Sor Juana Inés de la Cruz. II villancicos y letras sacras (México, D.F.: Fondo de Cultura Económica, 1952). 
ensayar los Maitines para el Niño con "Psamo y Antiphinine"-léase: salmos y antífonas-, pero el coro de negros no hace más que reírse de él:

"Quien, quien

Ja ja ja ja ja,

No puere tata Pascua

Polque pala sel cantola

E menestel la solfeona

Ja ja ja ja ja

Y que risa nosra".

El tata Pascual se irrita y los calla con indignación:

"Que Sofeona ni Sofíta, caya tus voca bobita [...] quere uté cayá, burego [...] que a mi nengún bufarón que me avía de burá quando emu sabiro e ceto, sendo como so tan preto, que toro puero enseña, yo sabe muy bie baylá".

Para ser cantor hay que saber solfeo, es decir, estar familiarizado con los principios de la teoría musical occidental, algo que -conforme al texto- no está al alcance de los negros. En este caso, lo que está en juego es la imposibilidad de acceso a un campo específico del saber por el hecho de formar parte de una etnicidad subalterna. La falta de competencia en música hace que el grupo de negros no tome en serio al tata Pascual, quien se rebela y afirma que ser prieto no es impedimento para enseñar. Finalmente, no le queda más que reconocer que lo único que sabe hacer es bailar y con ello refuerza el estereotipo asociado a los negros. Como contraparte podría argumentarse que la corrupción que el tata Pascual hace del rezo en latín -"Gloria Patri ra Firio e ro Pripritu Sianto, Oygaro uté Vitatorio que e cosa re Pugatorio"-podría indicar una suerte de irreverencia que subvierte el orden imperante.

En el villancico Antoniya, Flaciquiya, Gacipá un grupo de negros dialoga con una negra que sufre los efectos de la borrachera de la noche anterior:

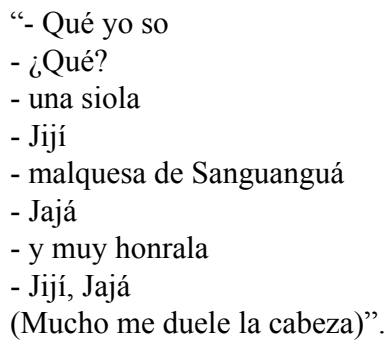


Es probable que el contacto con la elite blanca despierte en esta mujer pretensiones aristocráticas irrealizables, lo que suscita las burlas de los demás negros. La escena también pone en evidencia frustraciones derivadas de conflictos de género y clase; dado que la etnicidad es históricamente construida y se conecta con otras categorías de la diferencia -precisamente de clase y de género-, estas son ignoradas para crear la idea de que los negros conforman un grupo homogéneo que se integra a la comunidad cristiana en igualdad de condiciones. Con esto es posible ver que son diversas las categorías que se entrecruzan para definir una etnicidad impuesta desde afuera, aunque la categoría racial tiene preponderancia sobre todas las demás: los protagonistas asumen su identidad de "negros", que a veces opera como reivindicación y otras como negociación con la elite y sus modelos culturales.

En este punto es necesario detenerse y poner atención a los modos en que se exhibe la devoción cristiana en las negrillas. La proclama del cristianismo como verdadera fe significa para los negros alcanzar una posición ventajosa que no desperdician, puesto que les permite dignificarse como seres humanos que están en el lado correcto de la moral: ${ }^{39}$ son buenos porque tienen fe y tienen fe porque son buenos. Cuando la fe es fuerte se difuminan los signos de la alteridad y además se permite a los negros definir las formas en que manifiestan su devoción. Véase por ejemplo la tercera copla de Afuela, afuela:

\footnotetext{
“Adoramo al Niño Dioso

é también, a la Siola

é con toniya de Angola,

le ploculamo reposo,

duelme el Niño donoso,

plemiando la devosiona,

de lo Neglo y bona fé".
}

El Niño es adorado con prácticas culturales procedentes de África; como compensación por ello, restablecerá la justicia en el mundo. La narrativa centrada en Cristo es el punto de partida para anclar en la memoria colectiva la idea de que, en un estado de pobreza y exclusión, la fe es el camino para salvarse. En Lo neglo que somo gente se denuncia ante el Niño Jesús las vejaciones de las que son víctimas:

\footnotetext{
"Mi amo está un coxo, y me haze el también, pulque so su Neglo, andal en un pié, llevole a que Niño, ya que es Justo Juez,
}

39 Wimmer, "The Making and Unmaking...., 994. 


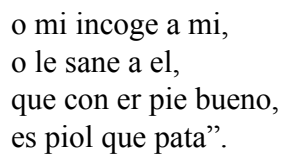

Dado que la Iglesia patrocina la creación de estos villancicos, el conflicto latente entre amos y esclavos queda neutralizado a través de la risa, además de que se consolida la figura de Cristo -"justo Juez"- como pilar del cristianismo y restablecedor de la paz social. En Ah, siolos molenos uno de los negros le lleva al Niño su jornal de todo el año -"pala que puela rescatal al Neglo"-, mientras que otro se entrega en ofrenda a sí mismo -"Pulque deya se silva le yebo tura mi pelsona, ni meno ni ma"- en una suerte de autosacrificio esperanzador.

El ser negro se yergue como antítesis de la blancura de Jesús, que es constantemente equiparado con la luz y la pureza. Esta dicotomía entre blancura y claridad en contraposición a negritud y pecado obliga a los negros a negociar constantemente las fronteras de su etnicidad: a pesar de que su piel es negra, tratan de demostrar que tienen el alma blanca. El intento de blanquearse lo hacen al adoptar la cultura blanca para ser admitidos socialmente. En A siñola plima mía, la pastora pide autorización para ir al portal de Belén e intenta esconder el color de su piel tras la blancura de las ovejas:

\footnotetext{
"Siola blanca no nos dexa,

digámosla a la Siñola

que si negla la Pastola,

tenemo branca la oveja".
}

En el caso de Digo a siola negra el sujeto protesta por los prejuicios negativos atribuidos al color de su piel: "Mi Bien, el neglo es pulquien, le, le, al mundo has viajaro, mi bien, que nos dice alguien, le, le, que es neglo el pecaro". Del mismo modo en que el pecado es negro, la negritud es concebida como una -negra- enfermedad. En la copla 4 de Cavayeroz, tulo neglo ezté puntual leemos: "Ben puriera e Niño, fa mi re, nacel neglo ya, zalambalapá, que ha de sanal nuestla negla enfelmedá, la, sol, fa".

Si bien el color de la piel impide que el negro se construya a sí mismo como un ser humano con plenos derechos, la fe es presentada como ruta esperanzadora hacia el blanqueamiento, aunque, a la postre, siempre será imposible de alcanzar. El resultado es un constante desplazamiento de las fronteras de la etnicidad que se negocia día a día mediante la expresión devocional.

No obstante, es difícil afirmar que los negros internalizan a cabalidad los discursos hegemónicos, más aún cuando resienten que se les restringe las opciones identitarias a las que pueden adscribirse. 


\section{Tropas amenazantes}

La expresión de la fe en Cristo no fue suficiente para hacer desaparecer las imágenes amenazantes que durante la era colonial circulaban en torno de los negros. Su arribo a Centroamérica fue de la mano con la llegada de los conquistadores. La abolición de la esclavitud indígena en 1542 propició que se otorgaran licencias y posteriormente asientos para la importación de esclavos africanos, ${ }^{40}$ aunque no debemos olvidar que un importante contingente ingresó por la vía del contrabando. Conforme al censo realizado en Santiago de Guatemala en el año 1604, en la ciudad residían unas 7.000 personas; de ellos, 1.390 eran esclavos negros, 225 esclavos mulatos, 380 mulatos libres y 10 negros libres. ${ }^{41}$ No hay datos claros respecto del número total que había en Centroamérica, pero se estima que durante todo el período de tráfico de esclavos pueden haber llegado a $\operatorname{los} 21.000 .{ }^{42}$

Para los indígenas locales los negros pronto se revelaron como servidores -y cómplices- del poder colonial. A principios de la década de 1570 las comunidades rurales del valle de Santiago de Guatemala escribieron al rey para denunciar los abusos y maltratos que sufrían por parte de los oficiales españoles, los vecinos de la ciudad y sus sirvientes mestizos y negros ${ }^{43}$. Así lo expresan los indígenas del Barrio de la Merced, quienes se quejan de que los negros esclavos de los oidores de la Real Audiencia los obligaban a vender el forraje para los caballos -"rastrojo"- a un precio inferior al del mercado:

\footnotetext{
"He aquí el sufrimiento de cuando nos empobrecieron los oidores, cuando vinieron a encargarnos de venderles rastrojo. En verdad lo hacemos, y no nos dan su valor. Además, nos maltratan sus [esclavos] negros. Ya no tenemos tierras donde sacar rastrojo que vender. Es muy poco con lo que vivimos. Es nuestra aflicción". ${ }^{44}$
}

Más adelante, en la Memoria 4 se denuncia que "[...] en la cárcel nos afligen los negros, los españoles y los mestizos, allá nos pegan". ${ }^{45}$ Esta situación se prolongó hasta los albores de la Independencia. En la visita que el arzobispo Pedro Cortés y Larraz realizó a la diócesis de Guatemala -1768-1770- observó que en

40 Véase: Juan Pablo Peña Vicenteño, "Relaciones entre africanos e indígenas en Chiapas y Guatemala", Estudios de Cultura Maya (México) 34 (enero, 2009), 167-180, en: http://www.scielo.org.mx/scielo. php?script $=$ sci arttext\&pid=S0185-25742009000200006

41 David Jickling, "The Vecinos of Santiago de Guatemala in 1604", en: Estudios del Reino de Guatemala, (ed.) Duncan Kinkead (Sevilla, España: Escuela de Estudios Hispanoamericanos de Sevilla, 1985), 90.

42 Véase: Vodovozova, A contribution to the History..., 29.

43 Este legajo fue encontrado en 1972 por Cristopher Lutz en el Archivo General de Indias, Sevilla. Véase: Karen Darkin y Christopher H. Lutz, Nuestro pesar, nuestra aflicción. Tunetuniliniz, tucucuca. Memorias en lengua náhuatl enviadas a Felipe II por indigenas del Valle de Guatemala hacia 1572 (México, D.F.: UNAM; Centro de Investigaciones Regionales de Mesoamérica, 1996), en: http://www.historicas.unam. $\mathrm{mx} /$ publicaciones/publicadigital/libros/nuestropesar/npesar.html

44 Lutz, Ibid., 7.

45 Lutz, Ibid., 17. 
San Cristóbal de Totonicapán había en la plaza un negro que agarraba de las manos a los indígenas mientras eran azotados. La razón de esto era que el Alcalde Mayor buscaba provocar más abatimiento en los indígenas al verse asidos por un negro. ${ }^{46}$ Severo Martínez Peláez señala que en 1811 un motín indígena estalló en Patzicía porque el tributo era cobrado con sumo rigor por un mulato, esbirro del alcalde mayor. ${ }^{47}$ En resumen, a pesar de las políticas de segregación que había dispuesto la Corona por la mala influencia que atribuía a los españoles, negros y mestizos sobre la población indígena, ${ }^{48}$ la norma nunca se cumplió. Esto generó espacios de interacción que dieron origen a castas conocidas como zambos, lo que contribuyó a enriquecer el perfil multiétnico del istmo centroamericano.

El aumento de la importación de esclavos africanos tuvo directa relación con las necesidades agrícolas -sobre todo la producción de azúcar en los ingenios de la orden dominica y la de añil-, el trabajo en las minas y el servicio doméstico. Muchos esclavos incluso fueron entrenados como artesanos. Cabe señalar que en Guatemala el sistema judicial español ofrecía a los esclavos espacios legales para defender sus derechos y comprar su libertad. De hecho, la mayoría lograba ahorrar y, con el apoyo de las redes familiares, lograba obtener la manumisión. ${ }^{49}$ Con el curso del tiempo se produjo un aumento constante de negros y mulatos libres que tenían bastante independencia de movimiento y de alguna u otra forma se integraron en la sociedad guatemalteca. No obstante, esto no minorizó las políticas de segregación y exclusión social de las que fueron víctimas. En las ordenanzas de Indias se detallan las infracciones que los hacía merecedores de castigo: huir, beber, dedicarse al juego, generar altercados, etc. Ya sea que se tratara de negros esclavos o negros libres, la violación de estas normas aumentaba la desconfianza hacia ellos, haciéndolos ver como un grupo proclive al desorden, el pillaje y la rebelión. ${ }^{50}$

A mediados del siglo XVII el viajero y fraile dominico inglés Thomas Gage escribió lo siguiente respecto de los esclavos que residían en las haciendas

46 Pedro Cortés y Larraz, Descripción geográfico-moral de la Diócesis de Goathemala, Tomos I y II (Guatemala: Tipografía Nacional, 1958).

47 Véase: Severo Martínez Peláez, Motines de indios. La violencia colonial en Centroamérica y Chiapas (Ciudad de Guatemala, Guatemala: F\&G Editores, 2011), 63.

48 Magnus Mörner, La Corona Española y los foráneos en los pueblos de indios de América (Madrid, España: Ediciones de Cultura Hispánica, 1999), 127.

49 Véase: Catherine Komisaruk. "Hacerse libre, hacerse ladino: Emancipación de esclavos y mestizaje en la Guatemala colonial", en: La negritud en Centroamérica, (eds.) Lowell Gudmunson y Justin Wolfe (San José, Costa Rica: EUNED, 2012), 204-205.

50 Mauricio Valiente, "El tratamiento de los no-españoles en las ordenanzas municipales indianas", Estudios de Historia Social y Económica de América (España) 13 (1996), 47-58, en: http://hdl.handle.net/10017/5921; Carmen Bernand, "Negros esclavos y libres en las sociedades hispanoamericanas" (2000), en: http:// www.larramendi.es/i18n/catalogo_imagenes/grupo.cmd?path; Beatriz Palomo de Lewin, "Perfil de la población africana en el Reino de Guatemala", en: Rutas de la esclavitud en África y Centroamérica, (comp.) Rina Cáceres (San José, Costa Rica: EUCR, 2001), 195-209; Aníbal Chajón Flores, El motín del Barrio San Jerónimo, en la ciudad de Santiago de Guatemala (1697-1701) (Tesis de Grado, Departamento de Historia de la Universidad Francisco Marroquín, Guatemala, 2000). 
de añil: "Aunque estos no tienen otras armas que un machete [...], sin embargo son tan desesperados, que muchas veces han causado alarmas a la ciudad de Guatemala, y se han hecho temer de sus mismos amos". ${ }^{51}$ Cuando el arzobispo Pedro Cortés y Larraz visitó la hacienda dominica de San Jerónimo, observó que "[...] hay esclavos que trabajan con perfección todo género de oficios necesarios, como albañilería, carretería, carpintería y fundición de metales para caldera y cuanto ocurra". ${ }^{52}$ Por otro lado, cuando se trata de negros o mulatos libres que residían en los pueblos, su postura es diferente. De la villa de San Vicente destaca que "los negros, mulatos y ladinos llevan una vida perversa y abandonada, sin temor de Dios ni del rey". ${ }^{53}$ El prelado concluye que tantos excesos solo podrán ser controlados "sacando tantos negros, mulatos y ladinos, que ya abruman el reino o poniéndolos en más sujeción". ${ }^{54}$

A pesar de estas imágenes contradictorias respecto de los negros, muchos fueron reclutados para integrar las milicias armadas. ${ }^{55}$ De hecho, en la cédula Real de 1663 se insta a formar compañías de mulatos, por ser ellos personas de valor que "pelean con brío y reputación", ${ }^{56}$ aunque ese mismo año se exigió prohibir el uso de armas a esclavos, mulatos y mestizos porque ocasionaban riñas y se volvían peligrosos para sus amos españoles. En el transcurso del siglo XVIII los Borbones reorganizaron las milicias del reino de Guatemala, en parte para hacer frente al avance de los ingleses en el Caribe, pero también para detener las incursiones hostiles de los zambos misquitos. ${ }^{57}$ Es así como en el Reglamento de 1755 se contempla la formación de un batallón de mestizos y mulatos, aunque para entonces ya representaban un número importante en las milicias, lo que les aseguraba cierto prestigio e integración en la sociedad colonial.

¿Cómo se relacionan estas milicias de negros y mulatos con las "tropas" que emergen en los villancicos de negros? La verdad es que no hay relación alguna. El texto las despoja de cualquier alusión bélica desde el momento en que se establece que su único cometido es rendir pleitesía al Niño Jesús en el Portal de Belén. Esto ilustra el modo en que las diferencias fenotípicas llegan a ser el principal marcador de la alteridad, independientemente de lo difusa que se torna la línea de segregación. Veamos algunos ejemplos. En el villancico Venga

51 Thomas Gage, Los viajes de Thomas Gage en la Nueva España, Tercera Parte, Capítulo II (Ciudad de Guatemala, Guatemala: Biblioteca de Cultura Popular, 1950), 23.

52 Pedro Cortés y Larraz, 294-295.

53 Ibid., 192.

54 Ibid., 193.

55 José Antonio Fernández señala que su tarea era defender a las colonias, sobre todo una vez que desapareció el servicio militar obligatorio que prestaban los encomenderos españoles. Véase: "Población afroamericana libre en la Centroamérica colonial”, en: Rutas de la esclavitud en África y América Latina, (comp.) Rina Cáceres (San José, Costa Rica: EUCR, 2001), 323-340.

56 Véase: Bernand, "Negros esclavos y libres...", 114; Salvador Montoya, "Milicias negras y mulatas en el reino de Guatemala (siglo XVIII)", Cahiers du monde hispanique et luso-brésilien (Francia), n. 49 (1987), 93-104, en: https://www.jstor.org/stable/40852784

57 Salvador Montoya, 95. 
turo Flanciquillo los negros entran en tropa al portal para danzar Matachines. ${ }^{58}$ En Pascualillo que me quieles se ordena a los negros que formen un escuadrón armado "de tura la gente negla, y vengan malchando turitos a pliesa -a prisacon las caravuzas -arcabuces-". También hay una tropa militar en Afuela, afuela, que exige a los transeúntes abrir paso al rey de Guinea.

Ya se señaló que la tropa de negros que marcha a Belén para adorar al Niño es un lugar común en los villancicos. No obstante, quisiera detenerme en Afuela, afuela porque la tropa de negros intenta imponer a los blancos la -absurda-prohibición de estornudar cuando pasa el rey de Guinea:

\author{
"Como lo branco estornura, \\ luego embalgamo tambaco, \\ entlamole ben a saco \\ como la Plaza de Bura, \\ no tenen casa segula, \\ ni vale pedil peldon \\ y apelan a San Joseph \\ le, le, le, ay Kirié, \\ ay Kirie, Kirieleyson. \\ Achí, achí, \\ Caya, caya beyaco, \\ Que te embalgalemo tambaco".
}

El texto señala dos amenazas dirigidas a los blancos: embargarles el tabaco y "entrar a saco". El Diccionario de Autoridades de 1732 define entrar a saco como una incursión violenta para hacer saqueo, "haciendo los soldados pillage de quanto encuentran en las casas y vecinos". Al considerar que en la época colonial los negros fugitivos formaban verdaderas milicias dedicadas al pillaje, la imagen evoca un temor latente que -otra vez- es matizado en el contexto de la celebración con el apoyo de la música. Si bien el blanco "bellaco" se atreve a estornudar, la intercalación de estornudos distribuidos en las tres voces cantantes termina por dotar a la escena de un carácter alegre y lúdico: ${ }^{59}$

58 Según consta en el Diccionario de Autoridades, matachines era una danza en la que intervenían cuatro, seis u ocho personas que al son de un tañido alegre hacían muecas y se daban golpes con espadas de palo y vejigas de vaca llenas de aire. El matachín llevaba un disfraz de varios colores ajustado al cuerpo.

59 Agradezco al profesor José Andrés Saborío por su ayuda en esta transcripción. 




Fuente: transcripción de M. M. José Andrés Saborío.

El tópico del estornudo también aparece en la sección introductoria de Diga plimiya. En este caso el grupo de negros le canta una tonada al Niño: "y aunque estornuden cantando, Señore, nadie les toca".

\section{De músicas y danzas}

La música en el ámbito de la fiesta baja la tensión del conflicto social. Si bien había algún grado de familiaridad con la música que los esclavos africanos hacían en las calles de las ciudades, tanto la diversidad de las prácticas musicales de origen africano como las funciones que esa música cumplía -ceremoniales, sociales, de iniciación, etc.- quedaron en la penumbra. La experiencia muestra que ciertas texturas y combinaciones sonoras fueron codificadas como típicas de los negros ${ }^{60}$ lo que quedó plasmado en los villancicos a través del uso del diálogo, la alternancia en las voces, las síncopas, hemiolas, suspensiones, contratiempos y diversas combinaciones de patrones rítmicos.

Aquí es necesario detenerse un momento en las grafías utilizadas. Los villancicos de este trabajo que datan del siglo XVII e inicios del siglo XVIII están en notación mensural blanca, utilizan clave de transporte ${ }^{61}$ y la métrica es $3 / 2$. Tal es el caso de Cavayeroz, tulo neglo ezté puntual, Pascualillo que me quieles, Negliya que quele y Siolo helmano Flacico. En los villancicos de Manuel José de Quirós hay diferentes sistemas de notación: Jesuclisa Mangalena y Venga turo Flanciquillo representan resabios de la notación mensural blanca -métrica 3/2-, mientras que en Digo a siola negla prevalece el sistema moderno, con métrica 6/8. En la última etapa del siglo XVIII, Rafael Antonio Castellanos adoptó definitivamente la notación moderna, al desarrollar procedimientos compositivos ajustados al sistema tonal. Así vemos, por ejemplo, que las particellas están en

60 Stevenson, “The Afro-American...", 496-497; Dieter Lehnhoff, "Letra y música...”, 57- 58.

61 Las claves de transporte se utilizaban en obras de tesitura muy alta e indican que el solista debía cantar una cuarta justa por debajo de la nota dada; estas eran: clave de sol en segunda línea para el Tiple, clave de do en segunda línea para el Alto, clave de do en tercera línea para el Tenor y clave de do en cuarta línea -o clave de fa en tercera línea- para el Bajo. 
clave natura ${ }^{62}$ y los cambios de sección suelen ir aparejados de un cambio de métrica $-3 / 8,6 / 8,3 / 4-$.

La música proporcionó un espacio compartido que favoreció procesos de hibridación. Cito por ejemplo la presencia de instrumentos musicales de origen diverso, como la guitarrilla - guitaliya-, bandurria -bandurriya-, rabel -rabé-, violín -viorín- y violón -viorón-. En el grupo de instrumentos de viento hay flautas -flauta, flautos, flautiya-, trompas -tompleton-y bajón, aunque los instrumentos mencionados con mayor frecuencia son los de percusión: tambores -tamboritiyo, tamboril-, sonajas -zonagillas - , pitos, pandero y adufe ${ }^{63}$-arufeSi bien predominan los instrumentos de factura europea, algunos de ellos son de origen árabe y otros constituyen variantes locales de instrumentos africanos. En Turu turu lo nenglito el grupo de negros le lleva al Niño "sonaja, chinchi, natambo, adufe y cascabé". Por su parte, la tropa de Digo a siola negla le ofrece al Niño una danza gloriosa con "las zonagillas, pitos panderos y flautos". En el villancico Afuela afuela hay un desplieque de cordófonos:

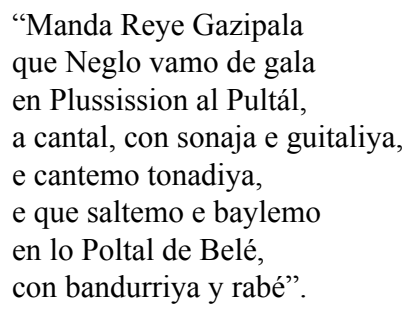

Cabe señalar que los instrumentos mencionados en el texto no necesariamente coinciden con la instrumentación que el compositor creó para el villancico en cuestión. Castellanos suele agregar una parte de violín -I y II- y continuo. Algunas piezas incorporan un Bajón o Trompas, aunque el hecho de que hasta el momento no se hayan encontrado más partes instrumentales no constituye una prueba irrefutable de que en su momento no las haya habido.

Las danzas y géneros musicales de origen africano tienen un lugar importante. En Venga turo Flanciquillo se anuncia "tocaremo la turumbella, cantaremo la zanguanguá"; en Cavayeroz tulo neglo esté puntual el canto dice "bueno za, bueno za y turo lo Neglo bolvamo a entoná, zulumbulupé, pol fa mi re, zalambalapá, pol la sol fa"; por último, en Lo neglo que somo gente cantan "qui se haga, y mas que palesca, barumbá, barumbá, barumbára". En el caso de Venga

62 Las claves naturales son: do en primera línea para el Tiple, do en tercera línea para el Alto, do en cuarta línea para el Tenor, fa en cuarta línea para el Bajo.

63 El adufe es definido en el Diccionario de Autoridades como cierto género de tamboril bajo y cuadrado similar al pandero. Es de origen árabe y usualmente lo usaban las mujeres para bailar. Véase Diccionario de Autoridades (Real Academia Española: 1726-1739), en: http://web.frl.es/DA.html 
turo Flanciquillo, las onomatopeyas ze, ze, ze y chi, chi, chi simulan el ruido que produce el cruce de espadas que hacen los que danzan.

Se observa que los elementos señalados marcan la diferencia cultural y muestran cómo la música reafirma los criterios para definir la etnicidad. Nótese que en Diga plimiya hay una percepción negativa de la música de los blancos:

\footnotetext{
"Cuando lo branco intenta, con voze destemplaro, al Infante alegraro, hace a lo pleto aflenta, pues canta impeltinente, con tlizte muziquiya".
}

A pesar de eso, más adelante los negros manifiestan orgullo porque conocen los géneros musicales occidentales, pero -otra vez- el error al pronunciarlos revela una ignorancia pretenciosa que los pone nuevamente en condición de inferioridad: minuetos -minuete-, arias -alie-, tonadas o tonadillas, ensaladas -ensarara-, canciones -cansioncilla-, villancicos - con su estrivillico- y matachines. Incluso se insinúa la ejecución de un baile de salón en "Afuela afuela":

\author{
"Tocamo la campaniya \\ y oldenamo Plussission, \\ cantando Kirieleyson \\ y responde la Capiya \\ tocando la bandurria, \\ danzando floreta, ${ }^{64}$ \\ al son, campanela ${ }^{65}$ y quatro pe \\ le le le, ay Kirie, \\ ay Kirie Kirieleyson". ${ }^{66}$
}

Un último aspecto que quisiera mencionar es la presencia de elementos locales en los villancicos de negros revisados en este trabajo. La estructura interna de las piezas mantiene el formato europeo, de manera que no es posible sostener que este fue lo suficientemente flexible como para propiciar una "adaptación" a las condiciones de cada lugar. Es posible que los procesos de hibridación se hayan manifestado más bien en la ejecución en vivo, aunque no podemos saberlo con certeza. En algunos ejemplos de villancicos sí hay referencias a la gastronomía de la zona, aunque no necesariamente se trata de una dieta de origen africano. En la copla 3 de El negro maytinero encontramos:

64 En el Diccionario de Autoridades es descrito como el movimiento de ambos pies en forma de flor.

65 Vuelta que se da con la pierna levantada. Diccionario de Autoridades.

66 En ocasiones la ejecución requería el uso de disfraces, según se observa en el grotesco desfile de personajes en Negliya que quele: "Jorgiyo de Angola vestido de Anguila, delante de Reye, baylando camina [...] Antona de Congo, de mico veztira/ sobre un gran cameya, va haciendo baynica [...] Flasico volteando como arliquiniya, en vez de maroma piza una sardina". 
"A sus sobrinos y nieto combida que oygan pasar, de sus Maytines el guiso, de solomos en Pipiam".

El solomo en Pipiam -pepián- es carne en una salsa elaborada a base de semillas de calabaza, ajonjolí y otras especias tostadas; aún hoy en día forma parte de la gastronomía de Guatemala. También en el villancico Ah, siolos molenos hay una alusión a la comida de la zona, puesto que los negros le llevan como ofrenda al Niño arrope de calabaza -"calambaza te aRope"-, rosquilla y chocolatiya de Oaxaca. Respecto de esto, habría que investigar con mayor profundidad los alcances de la transferencia cultural -multidireccional- durante el período de colonización española,${ }^{67}$ pero eso supera los límites de este trabajo.

\section{Conclusiones}

Según se observó, la etnicidad es construida en los villancicos a partir de una mirada externa que reproduce narrativas de la diferencia como fenómeno real e inmutable. A pesar de la naturaleza multidireccional de los procesos de transferencia cultural, el "negro" no es construido en tanto sujeto histórico, capaz de definir su identidad en términos propios, sino que permanece como una categoría petrificada e inmutable cuyo distintivo es -además del color de la piel- la alegría, devoción e inocencia, en un permanente estado de minoría de edad.

En cuanto a la música, pudo observarse que los maestros de capilla en Hispanoamérica continuaron la tradición de utilizar procedimientos compositivos específicos para remitir a las prácticas musicales de los esclavos africanos: diálogo entre un solista y el coro -de negros-, uso de múltiples instrumentos de percusión, onomatopeyas, danzas, ritmo vivaz, etc. El efecto de ello fue la proliferación de piezas musicales donde la figura del negro aparece esquematizada.

Los villancicos también ponen sobre la palestra las tensiones sociales que subyacían en el orden colonial, de manera que en ocasiones adquieren un matiz de denuncia. La figura amenazante del negro pendenciero va acompañada de discursos reivindicativos que contienen expresiones contra los blancos. El lamento por la condición social del negro -o su negritud- revela que la etnicidad se yergue como una lucha política y simbólica por el lugar en el campo social, aunque, si bien se plantea una suerte de válvula de escape, lo cierto es que los conflictos quedan siempre neutralizados con la presencia de el Niño, la devoción, el humor y las prácticas artísticas -música, danza, teatro- como facilitadoras de la reconciliación social. Se trata de artificios que encuentran espacios para liberar las voces subalternas, más allá de los diferentes niveles en que se construye su etnicidad.

67 Véase: Peña Vicenteño. 
Con base en lo expuesto, sostengo que los villancicos de negros cumplían una función política, puesto que el hecho de incorporar a los afrodescendientes en la fiesta pública y exhibir su diferencia, forma parte de las estrategias institucionales para construir límites étnicos que prevalecen sobre los conflictos de clase. A pesar de todo, estas piezas creaban la ilusión de una comunidad unida en torno de los valores universalizantes de la cultura occidental. El júbilo inocente celebra el tiempo efímero en el que la subalternidad es transformada en espectáculo, mientras las estructuras de poder se fortalecen y eternizan. 